Article

\title{
Extraction of Phosphorous from a Phosphorous-Containing Vanadium Titano-Magnetite Tailings by Direct Flotation
}

\author{
Junhui Xiao ${ }^{1,2,3, * \mathbb{D}}$, Chao Chen ${ }^{1,2, *}$, Wei Ding ${ }^{1}$, Yang Peng ${ }^{1}$, Tao Chen ${ }^{1}$ and Kai Zou ${ }^{1}$ \\ 1 Sichuan Provincial Engineering Lab of Non-Metallic Mineral Powder Modification and High-Value \\ Utilization, Southwest University of Science and Technology, Mianyang 621010, China; \\ dingwei@mails.swust.edu.cn (W.D.); pengyang@mails.swust.edu.cn (Y.P.); \\ chentao@mail.swust.edu.cn (T.C.); zoukaiswust@163.com (K.Z.) \\ 2 Institute of Multipurpose Utilization of Mineral Resources, Chinese Academy of Geological Sciences, \\ Chengdu 610041, China \\ 3 Key Laboratory of Sichuan Province for Comprehensive Utilization of Vanadium and Titanium Resources, \\ Panzhihua University, Panzhihua 617000, China \\ * Correspondence: xiaojunhui@swust.edu.cn (J.X.); fanshanping@swust.edu.cn (C.C.)
}

Received: 2 July 2020; Accepted: 17 July 2020; Published: 20 July 2020

\begin{abstract}
In this study, there is $1.42 \% \mathrm{P}_{2} \mathrm{O}_{5}$ in the P-containing V-Ti magnetite tailings in Miyi Region of China, with the valuable minerals mainly including apatite, and aluminosilicate minerals as the main gangue components. The direction flotation process was used to recover phosphorous from the low-grade phosphorous-bearing V-Ti magnetite tailings. The results showed that an optimized phosphorous concentrate with a $\mathrm{P}_{2} \mathrm{O}_{5}$ grade of $31.35 \%$ and $\mathrm{P}_{2} \mathrm{O}_{5}$ recovery of $88.02 \%$ was obtained by flotation process of one roughing, three scavengings, and three cleanings under roughing conditions, which employed pulp pH of 9, grinding fineness of $<0.039 \mathrm{~mm}$ occupying $90 \%$, flotation concentration of $25 \%$, and dosages of carboxymethylcellulose, oxidized paraffin wax soap, and pine oil of $400 \mathrm{~g} / \mathrm{t}, 300 \mathrm{~g} / \mathrm{t}$, and $20 \mathrm{~g} / \mathrm{t}$, respectively. Optimized one scavenging, two scavenging, and three scavenging conditions used a pulp $\mathrm{pH}$ of 9, and dosages of carboxymethylcellulose, oxidized paraffin wax soap, and pine oil of $200 \mathrm{~g} / \mathrm{t}, 150 \mathrm{~g} / \mathrm{t}, 10 \mathrm{~g} / \mathrm{t} ; 100 \mathrm{~g} / \mathrm{t}, 75 \mathrm{~g} / \mathrm{t}$, and $5 \mathrm{~g} / \mathrm{t}$; and $100 \mathrm{~g} / \mathrm{t}$, $75 \mathrm{~g} / \mathrm{t}$, and $5 \mathrm{~g} / \mathrm{t}$, respectively. Optimized one cleaning, two cleaning, and three cleaning condition dosages of carboxymethylcellulose of $100 \mathrm{~g} / \mathrm{t}, 50 \mathrm{~g} / \mathrm{t}$, and $25 \mathrm{~g} / \mathrm{t}$, respectively. Study of analysis and characterization of phosphorous concentrate by X-ray diffraction (XRD), scanning electron microscopy (SEM), and energy dispersive spectroscopy (EDS) show that most gangue minerals enter the flotation tailings, the main minerals in phosphorous concentrate are apatite, olivine, and feldspar.
\end{abstract}

Keywords: phosphorous; apatite; vanadium titano-magnetite tailings; direct flotation

\section{Introduction}

Phosphorus is an important non-metallic mineral resource, which is widely used in agriculture, chemical industry, medicine, food, and other industrial sectors. The global phosphate mineral resources are very rich, but the distribution is extremely uneven, among which the phosphate mineral reserves in Morocco and Western Sahara, China, and Syria account for more than $80 \%$ of the total proved phosphorus reserves in the world. With the continuous exploration and development of global phosphate ore, high grade of $\mathrm{P}_{2} \mathrm{O}_{5}$ and low harmful impurities of high-quality phosphate ore resources are gradually decreasing, the overall development of global phosphate ore resources is developing towards the direction of low-quality phosphate ore resources [1]. 
According to the statistical data of the international fertilizer organization, it was concluded that the decline in the global raw ore quality leads to the continuous decline in the proportion of the world's $\mathrm{P}_{2} \mathrm{O}_{5}$ grade to more than $32 \%$ of the high-quality commodity phosphate ore. $\mathrm{P}_{2} \mathrm{O}_{5}$ grade has been an important supply source of phosphorus around the world in recent years. $\mathrm{P}_{2} \mathrm{O}_{5}$ grade and below $30 \%$ of the proportion of phosphate ore development is continuing to increase, and this is expected to take a very important market share in the future. Although in the long run, the global phosphate mining is developing towards the direction of low-quality phosphate mining, in the short term, with the large-scale development of high-quality phosphate mining in Morocco and other countries in North Africa, the global high-quality phosphate mining resources will account for a relatively large proportion of the development [2-5].

There are about 120 kinds of known phosphate minerals in nature, which are widely distributed. The earth could be a phosphorus resource and utilization of phosphate rock minerals if apatite, in igneous, sedimentary, metamorphic ore deposits are formed, its output accounts for about $95 \%$ of the total output. Apatite minerals can form the base for five kinds of mineral deposits: Fluorapatite, hydroxyapatite, carbon hydroxyapatite, francolite, and kursk stone. Other available phosphate minerals include refractory svanbergite, struvite, and blue-iron stone. The average grade of phosphorus resources in China is low, and it contains high impurities such as $\mathrm{MgO}, \mathrm{Al}_{2} \mathrm{O}_{3}$, and $\mathrm{Fe}_{2} \mathrm{O}_{3}$, which is difficult to select. The phosphate ore dressing process mainly includes scabbing-stripping, flotation, and heavy medium dressing. In 2018 , the national average recovery rate was $86.1 \%$, among which the average recovery rate was $94.3 \%$ for the cleaning and desilting process, $86.9 \%$ for the flotation process, and $83.5 \%$ for the heavy medium processing process. Due to the different occurrence conditions of phosphate ore resources, the grade of phosphate ore in the main phosphate ore areas is quite different. The grade of phosphate ore in Hubei province is about $20 \%$, and in the Yunnan and Guizhou provinces it is $24 \%$. With the continuous exploitation of phosphate ore resources, the ore grade is decreasing. Theoretically, the technology of phosphate ore grade reduction is feasible, but economic rationality is the key factor [6-8].

According to the mineralogical characteristics of phosphate ore, the phosphate ore treatment process includes flotation, attrition scrubbing and desliming, electrostatic separation, magnetic separation, gravity separation, acid leaching, and calcination. The application of attrition scrubbing and desliming, magnetic separation, and gravity separation should be referred to the characteristics of the phosphate ores in chemical composition and texture. In that case, the pre-concentration of valuable minerals and cost reduction are achieved. For example, coarser phosphate concentrates are obtained when using attrition scrubbing, desliming, and gravity separation to beneficiate weathered phosphate ores and banded structural sedimentary phosphate ores, respectively. Subsequently, the ultrafine components and overflow products are subjected to flotation for the further recovery of phosphate minerals. Due to the high efficiency in the removal of silicate and carbonate gangue minerals, froth flotation is dominantly employed for the beneficiation of phosphate ore, especially for low-grade sedimentary phosphate rocks. Generally, direct flotation by anionic surfactants or reverse flotation by cationic surfactants are conducted to remove the silicate gangues from phosphate. The phosphate ores mainly contain the siliceous phosphate rock, calcareous phosphate rock, and calcareous-siliceous phosphate rock. Both of the anionic direct flotation and cationic reverse flotation are applied for the beneficiation of siliceous phosphate rock, while the single anionic reverse flotation is preferred to beneficiate the calcareous phosphate rock [9-14].

Apatite in V-Ti magnetite ore is a kind of accessory mineral widely distributed. The content of apatite varies greatly in different ores in different mining areas and ore sections. It is mainly concentrated in gabbro type ores, while other types are only distributed sporadically or rarely appear. The content of apatite in Taihe and Hongge mining areas is relatively high, generally $1 \%$ to $9 \%$. Although the grade of associated phosphorus in vanadium titanium magnetite tailings in Panxi is low, and it may be a valuable element for comprehensive utilization due to its certain enrichment channels, which can promote the economical and intensive utilization of resources. After the comprehensive utilization of phosphate 
minerals, the content of phosphate minerals in tailings will be further reduced, which can reduce the pollution of soil caused by phosphorus in tailings. At the same time, the comprehensive utilization of phosphorus can effectively promote the new round of research on associated valuable elements in the Miyi region of China, and has a certain promoting effect on improving the comprehensive utilization process of V-Ti magnetite resources [15-19].

\section{Materials and Methods}

\subsection{Sampling}

The ore samples used in this study were from a low-grade phosphorus-containing vanadium titano-magnetite tailings produced by a concentrator in Miyi region after recovering iron and titanium using magnetic separation and flotation. The particle size was between 0.019 and $3.0 \mathrm{~mm}$. It was found that the blend ore samples were all caused by fine-grained caking. In order to ensure that the sample is representative, the agglomerated samples were crushed and then shrunk in advance for reserve. The main chemical composition analysis of the P-bearing V-Ti magnetite tailings is shown in Table 1, and the grain size analysis of the samples is shown in Table 2. The main mineral composition of the P-bearing V-Ti magnetite tailings is shown in Figure 1. The content of silicoaluminate mineral is higher, and the main minerals contain apatite, hornblende, feldspar, serpentine, chlorite, mica, quartz, dolomite, and calcite in the vanadium titano-magnetite tailings.

Table 1. Main chemical composition analysis of the P-Containing V-Ti magnetite tailings (\%).

\begin{tabular}{cccccccccc}
\hline $\mathrm{Fe}$ & $\mathrm{TiO}_{2}$ & $\mathrm{~S}$ & $\mathrm{P}_{\mathbf{2}} \mathrm{O}_{5}$ & $\mathrm{Na}_{2} \mathrm{O}$ & $\mathrm{K}_{2} \mathrm{O}$ & $\mathrm{CaO}$ & $\mathrm{Al}_{2} \mathrm{O}_{3}$ & $\mathrm{MgO}$ & $\mathrm{SiO}_{2}$ \\
\hline 6.73 & 2.73 & 0.132 & 1.42 & 6.29 & 1.06 & 12.86 & 22.29 & 13.67 & 30.73 \\
\hline
\end{tabular}

Table 2. A grain size analysis of the P-Containing V-Ti magnetite tailings (\%).

\begin{tabular}{ccccc}
\hline \multirow{2}{*}{ Fraction $(\mathbf{m m})$} & \multicolumn{2}{c}{ Yield } & $\mathbf{P}_{\mathbf{2}} \mathbf{O}_{\mathbf{5}}$ Content & $\mathbf{P}_{\mathbf{2}} \mathbf{O}_{\mathbf{5}}$ Distribution \\
\cline { 2 - 3 } & Individual & Cumulative & & \\
\hline$-5.00 \sim+3.00$ & 3.56 & 3.56 & 0.56 & 1.39 \\
$-3.00 \sim+2.00$ & 4.18 & 7.74 & 0.78 & 2.27 \\
$-2.00 \sim+1.00$ & 6.99 & 14.73 & 0.43 & 2.10 \\
$-1.00 \sim+0.50$ & 9.23 & 23.96 & 1.12 & 7.21 \\
$-0.50 \sim+0.25$ & 8.36 & 32.32 & 0.79 & 4.61 \\
$-0.25 \sim+0.154$ & 10.67 & 42.99 & 1.02 & 7.60 \\
$-0.154 \sim+0.100$ & 15.22 & 58.21 & 0.99 & 10.51 \\
$-0.100 \sim+0.074$ & 10.96 & 69.17 & 1.05 & 8.03 \\
$-0.074 \sim+0.038$ & 12.33 & 81.5 & 2.23 & 19.18 \\
$-0.038 \sim+0.019$ & 11.22 & 92.72 & 2.89 & 22.62 \\
$-0.019 \sim 0$ & 7.28 & 100 & 2.85 & 14.48 \\
Totals & 100.00 & & 1.43 & 100.00 \\
\hline
\end{tabular}

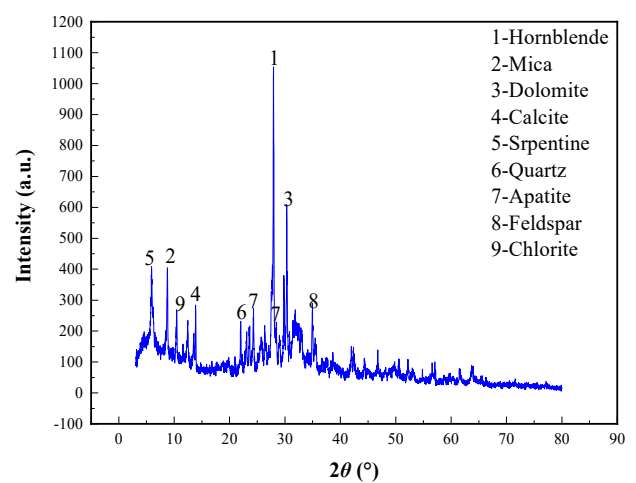

Figure 1. XRD diffractograms of the P-Containing V-Ti magnetite tailings. 


\subsection{Flotation Reagent and Equipment}

The main chemical reagents used in this experiment are oleic acid, oxidized paraffin soap, hydroximic acid, benzyl arsenic acid, sodium bicarbonate, lime, sodium carbonate, sodium hydroxide, sodium hexametaphosphate, carboxymethylcellulose (CMC), sodium fluosilicate, and sodium silicate, all of which have analytical purity and a producing area Shanghai AiBi Chemistry Preparation Co., Ltd., Shanghai, China.

The main equipment used in the flotation test included an XFD-1.5 L machine (Jinlin Exploration Machinery Plant, Changchun, China), an XFD-1.0 L hanging tank flotation machine (Jinlin Exploration Machinery Plant, Changchun, China), a cone ball mill (XMQ- $\Phi 240 \times 90 \mathrm{~mm}$, Jilin Exploration Machinery Factory, Changchun, China), disc grinder $(\Phi 300 \times 150 \mathrm{~mm}$, Jilin Exploration Machinery Factory, Changchun, China), drying box (Shanghai Shiyan Yan Electric Furnace Co., Ltd. Shanghai, China), and vacuum filter ( $\Phi$ 300, Southwest Chengdu Experimental Equipment Co., Ltd. Chendu, China).

\subsection{Procedure Design}

Flotation (roughing, scavenging), aimed at increasing the $\mathrm{P}_{2} \mathrm{O}_{5}$ grade and phosphorous recovery of phosphorous concentrate, was carried out using an XFD-1.5 L hanging tank flotation operating at a spindle speed of $1650 \mathrm{r} / \mathrm{min}$. A $500 \mathrm{~g}$ mass of phosphorous containing vanadium-titanium magnetite tailings was added to the $1.5 \mathrm{~L}$ flotation tank. Flotation (cleaning), aimed at increasing the $\mathrm{P}_{2} \mathrm{O}_{5}$ grade of phosphorous concentrate, was carried out using an XFD-1.0 L hanging tank flotation machine (Jinlin Exploration Machinery Plant, Changchun, China) operating at a spindle speed of $1650 \mathrm{r} / \mathrm{min}$. A 200-300 g mass of phosphorous concentrate was added to the 1.0 L flotation tank. Distilled water $(1.0 \mathrm{~L})$ was added and the pulp stirred and mixed for about $3 \mathrm{~min}$, followed by adjustment to the required $\mathrm{pH}$ using $\mathrm{NaOH}, \mathrm{NaHCO}_{3}, \mathrm{CaO}$, or $\mathrm{Na}_{2} \mathrm{CO}_{3}$. After $5-10$ min of pulping, the depressants were added to the slurry and conditioned for about $3 \mathrm{~min}$. Then, the collectors for improving phosphorous grade and recovery were added and agitated for about $3 \mathrm{~min}$. Before aeration, the frothers (pine oil) for improving the bubble were added, with another about $3 \mathrm{~min}$ of stirring. After about 3 min of flotation, the froth (phosphorous concentrate) and in-tank product (flotation tailings) were separately filtered, dried at $85{ }^{\circ} \mathrm{C}$ for $1.5-2 \mathrm{~h}$, and weighed. Quantitative analyses of phosphorous grade were conducted to calculate the phosphorous recovery. Calculation of the phosphorus recovery is shown in Equation (1).

$$
\text { Phosphorus recovery }=\left(\mathrm{Q}_{1} \times \beta_{1}\right) /\left(\mathrm{Q}_{1} \times \beta_{1}+\mathrm{Q}_{2} \times \beta_{2}\right) \times 100 \%
$$

where, $Q_{1}$ is the weight of phosphorus concentrate $/ g, Q_{2}$ is the weight of flotation tailings $/ g$, $\beta_{1}$ is the $\mathrm{P}_{2} \mathrm{O}_{5}$ content of phosphorus concentrate/\%, and $\beta_{2}$ is the $\mathrm{P}_{2} \mathrm{O}_{5}$ content flotation tailings/\%.

\subsection{Analysis and Characterization}

The chemical composition of P-containing vanadium titano-magnetite tailings, phosphorus concentrate, and flotation tailings was analyzed by a Z-2000 atomic absorption spectrophotometer (Hitachi Co., Ltd. Tokyo, Japan). The mineral phase compositions of P-containing vanadium titano-magnetite tailings, phosphorus concentrate, and flotation tailings were analyzed by X-ray diffraction (XRD, X Pert pro, Panaco, The Netherlands). The microstructure of the solid products was observed by SEM (S440, Hirschmann Laborgerate GmbH \& Co. KG, Eberstadt, Germany) equipped with an energy-dispersive X-ray spectroscopy (EDS) detector (UItra55, CarlzeissNTS GmbH, Hirschmann Laborgerate GmbH \& Co. KG, Eberstadt, Germany). 


\section{Results and Discussion}

\subsection{Effect of Different Collectors}

The commonly used collectors for phosphate ore flotation include oleic acid, sodium oleate, oxidized paraffin soap, hydroxamic acid, and benzyl arsenate, among which oleic acid, sodium oleate, oxidized paraffin soap, and other fatty acid collectors have a wide range of sources, low price, mild reaction conditions, and can achieve phosphate mineral flotation under alkaline conditions. Oxidized paraffin soap $\left(\mathrm{RCO}_{2} \mathrm{Na}\right)$ contains more than $\mathrm{C}_{18}-\mathrm{C}_{32}$ long chain fatty acids, and can form complexes on the surface of various mineral metals, which can greatly improve the hydrophobicity of the mineral surface, and at the same time have foaming property, so it can replace anion harvesters of various fatty acid soaps and be used in the flotation of various mineral products. Hydroxyl oxime arsenic acid and benzyl arsenic acid contain a toxic element and have strong foaming performance, then in the process of flotation test, we found that when the flotation foam is bigger with more viscosity, the water content is high, which eventually led to the foam product of phosphorus grade and recovery index was not ideal [20-22].

Results in Figure 2 reveal that the selectivity of oleic acid in the flotation process is relatively poor, which also leads to the lower phosphorus grade and recovery of the obtained flotation phosphorus concentrate. Oleic acid, oxidized paraffin soap, hydroxamic acid, and benzyl arsenic acid can realize the flotation of phosphate minerals. The flotation effect of oxidized paraffin soap as a collector is the most obvious, and phosphorus concentrate with a $\mathrm{P}_{2} \mathrm{O}_{5}$ grade of $12.65 \%$, and $\mathrm{P}_{2} \mathrm{O}_{5}$ recovery of $65.31 \%$ can be obtained. Therefore, oxidized paraffin is suitable as a flotation collector.

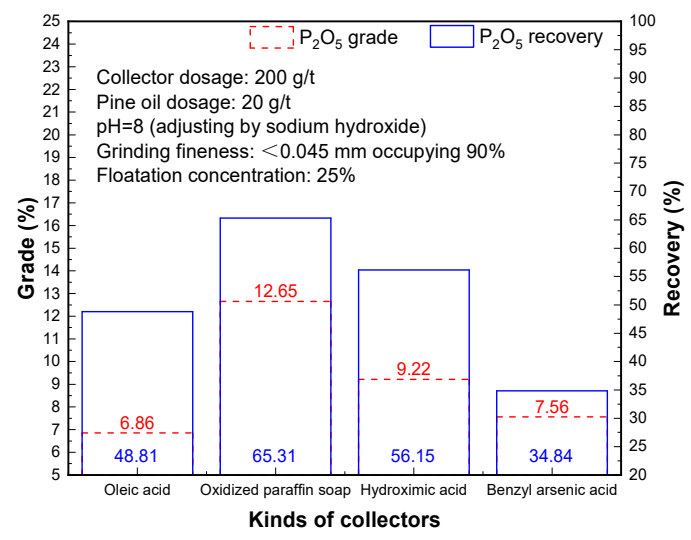

Figure 2. Effect of different collectors on extracting phosphorous.

\subsection{Effect of Oxidized Paraffin Soap Dosage}

In the process of flotation, the function of the collector is to strengthen the mineral adhesion to the foam, so as to change the hydrophobicity of the mineral surface, so as to realize the purpose of the mineral entering the flotation foam and becoming the concentrate product [23-25].

It is known from Figure 3 that the amount of oxidized paraffin soap can improve the flotation index of phosphorus concentrate. When the amount of oxidized paraffin was in the range of 100-300 g/t, the $\mathrm{P}_{2} \mathrm{O}_{5}$ grade of phosphorus concentrate decreased from $13.66 \%$ to $12.05 \%$, and the $\mathrm{P}_{2} \mathrm{O}_{5}$ recovery rate increased from $59.80 \%$ to $66.28 \%$. When the dosage of oxidized paraffin soap ranged from $400-600 \mathrm{~g} / \mathrm{t}$, the $\mathrm{P}_{2} \mathrm{O}_{5}$ grade of phosphorus concentrate decreased from $10.65 \%$ to $7.56 \%$, and the $\mathrm{P}_{2} \mathrm{O}_{5}$ recovery increased from $66.62 \%$ to $69.34 \%$. It shows that increasing the amount of collector is beneficial to improving the separation index of phosphate concentrate, but too much is not conducive to the flotation of phosphate minerals, and other minerals are easy to be floated, thus affecting the quality of concentrate products. Therefore, oxidized paraffin soap dosage of $300 \mathrm{~g} / \mathrm{t}$ is reasonable, and phosphorous concentrate with a $\mathrm{P}_{2} \mathrm{O}_{5}$ grade of $12.05 \%$ and $\mathrm{P}_{2} \mathrm{O}_{5}$ recovery of $66.28 \%$ was obtained. 


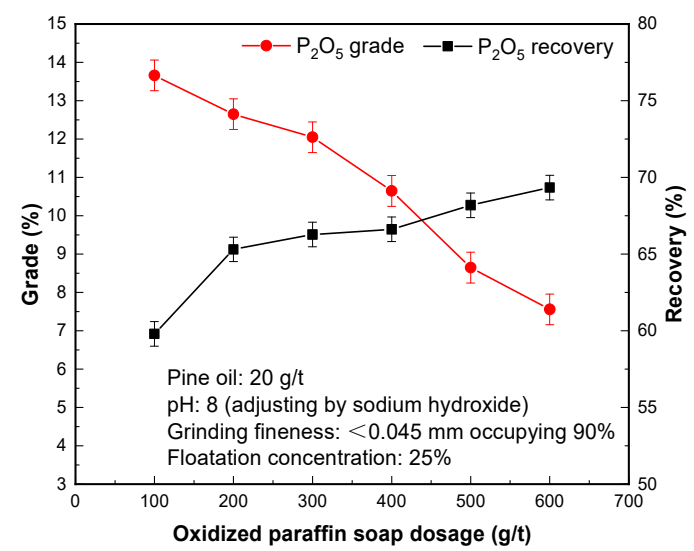

Figure 3. Effect of oxidized paraffin soap dosage on extracting phosphorous.

\subsection{Effect of Different Depressants}

The main gangue minerals in the vanadium titanium magnetite tailings contain mica, feldspar, chlorite, hornblende, and other silica-aluminate minerals. The common depressants of gangue minerals are sodium silicate, sodium hexametaphosphate, sodium fluorosilicate, and carboxymethyl cellulose. The results in Figure 4 show that the addition of carboxymethyl cellulose as an inhibitor is the most obvious to improve the quality of phosphorus concentrate. Carboxymethylcellulose molecule is composed of a number of glucose units, each unit of glucose with three base, namely in the $C_{2}$ and $C_{3}$ position para hydroxy and primary hydroxyl in $\mathrm{C}_{6}$ location, and the base to compare live dial by the base of the extent of the hydrogen atoms are replaced by carboxymethyl called substitution degree, the higher the degree of substitution of spindle methyl cellulose charged, the more easily dissolved in the aqueous solution. In aqueous solution, carboxymethylcellulose or ionization which makes its molecular burden on electric carboxymethylcellulose with slurry surface, make the slime superficiality magnesium silicate minerals which are the main gangue mineral, this kind of ore including serpentine, hornblende, and olivine changes, thereby corresponding inhibition [26-29].

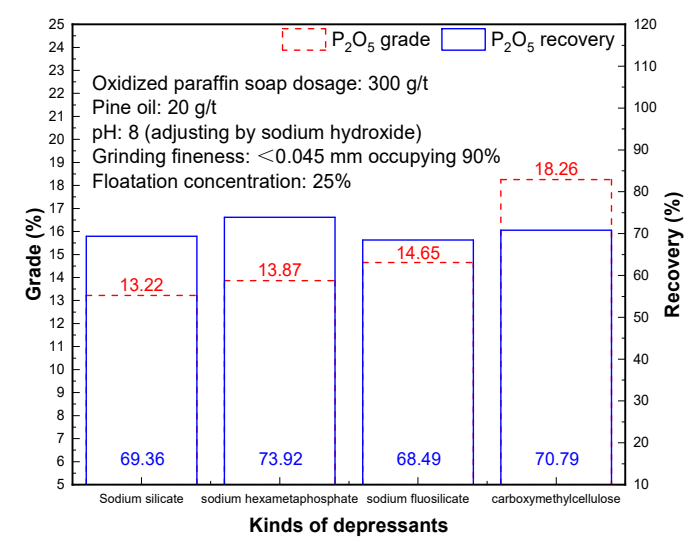

Figure 4. Effect of different depressants on extracting phosphorous.

Therefore, the highest $\mathrm{P}_{2} \mathrm{O}_{5}$ recovery of phosphate concentrate obtained by sodium hexametaphosphate as a depressant was $73.92 \%$, and the highest $\mathrm{P}_{2} \mathrm{O}_{5}$ grade of carboxymethyl cellulose as an inhibitor of phosphate concentrate was $18.26 \%$. After comprehensive consideration, phosphorous concentrate with a $\mathrm{P}_{2} \mathrm{O}_{5}$ of $18.26 \%$ and $\mathrm{P}_{2} \mathrm{O}_{5}$ recovery of $70.79 \%$ can be obtained by selecting carboxymethylcellulose as the depressant of the flotation process. 


\subsection{Effect of Depressant Dosage}

The purpose of adding carboxymethylcellulose is to enhance the hydrophilicity of gangue minerals, weaken the effect between the gangue minerals and the collectors, and, thus, to strengthen the separation of gangue minerals from apatite. Increasing the dosage of carboxymethylcellulose is beneficial to improving $\mathrm{P}_{2} \mathrm{O}_{5}$ grade and recovery of phosphorus concentrate.

The test results in Figure 5 show that the appropriate addition of carboxymethylcellulose as an inhibitor can improve the effect of phosphorus flotation; too little, and the degree of inhibition of gangue ore is not enough and too much, and it is easy to interfere with the target mineral, but led to gangue mineral into phosphorus concentrate, affecting the quality of phosphorus concentrate products. Carboxymethylcellulose is a polymer inhibitor, and can produce flocculation to fine minerals. When the amount is too large, it will interfere with the separation of phosphate minerals, reduce the phosphorus grade, and recovery of phosphorus concentrate products [30]. It is reasonable to use $400 \mathrm{~g} / \mathrm{t}$ carboxymethylcellulose, and a phosphorous concentrate with a $\mathrm{P}_{2} \mathrm{O}_{5}$ of $22.53 \%$ and $\mathrm{P}_{2} \mathrm{O}_{5}$ recovery of $72.51 \%$ can be obtained.

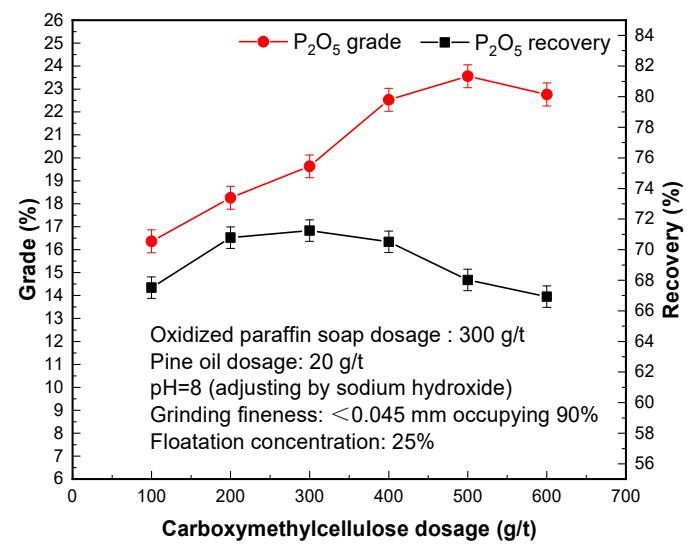

Figure 5. Effect of carboxymethylcellulose dosage on extracting phosphorous.

\subsection{Effect of Grinding Fineness}

Apatite and fine-grained gangue minerals are inset and symbiosis in the form of mechanical mixing. It is necessary to achieve high grinding fineness to realize monomer dissociation of most gangue minerals such as collophosphate and quartz. However, if grinding fineness is too high, over-grinding will occur, and the sorting effect will be reduced.

Results in Figure 6 show that with the increase of grinding fineness, $\mathrm{P}_{2} \mathrm{O}_{5}$ grade of phosphorus concentrate changed regularly. When $<0.038 \mathrm{~mm}$ occupying $90 \%$, the maximum value of $\mathrm{P}_{2} \mathrm{O}_{5}$ grade is $25.63 \%$. The $\mathrm{P}_{2} \mathrm{O}_{5}$ grade of concentrate begins to decline with grinding fineness increasing. The principle is that with the increase of grinding fineness, the dissociation degree of mineral monomer increases continuously, but when the grinding fineness is too high, it will result in over-grinding phenomenon, gangue minerals float up in large quantities, causing the grade of concentrate to drop. After comprehensive consideration of the concentrate grade and recovery, grinding fineness $<0.039 \mathrm{~mm}$ occupying $90 \%$ of phosphorous flotation, and phosphorous concentrate with a $\mathrm{P}_{2} \mathrm{O}_{5}$ grade of $25.63 \%$ and $\mathrm{P}_{2} \mathrm{O}_{5}$ recovery of $70.26 \%$ can be obtained. 


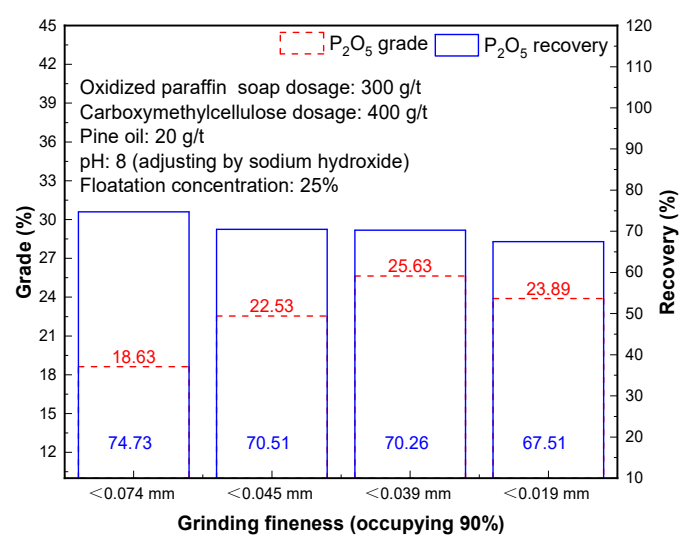

Figure 6. Effect of grinding fineness on extracting phosphorous.

\subsection{Effect of Pulp $\mathrm{pH}$}

The effect of different flotation $\mathrm{pH}$ values on phosphorus flotation separation is shown in Figure 7. In the process of flotation, the $\mathrm{pH}$ value of the pulp has a great influence on the physical and chemical properties of the mineral surface, especially whether the flotation agents can produce a certain physical or chemical adsorption on the mineral, so as to achieve the wettability change between the target mineral and non-target mineral [31]. Increasing the $\mathrm{pH}$ value of flotation pulp is beneficial to raising $\mathrm{P}_{2} \mathrm{O}_{5}$ grade of phosphorus concentrate. When the $\mathrm{pH}$ value exceeds $9, \mathrm{P}_{2} \mathrm{O}_{5}$ grade and recovery of phosphorus concentrate begin to decrease, indicating that slurry flotation at $\mathrm{pH}=9$ is conducive to the separation of phosphate minerals. The $\mathrm{P}_{2} \mathrm{O}_{5}$ grade and $\mathrm{P}_{2} \mathrm{O}_{5}$ recovery of phosphorus concentrate were $28.33 \%$ and $73.64 \%$, respectively.

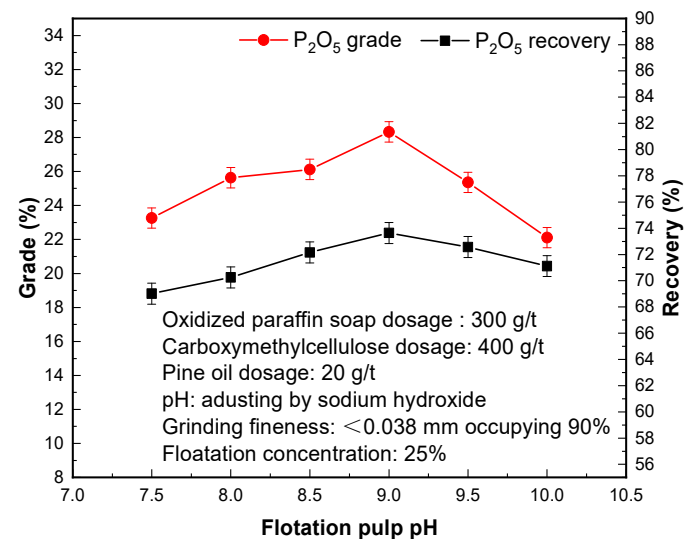

Figure 7. Effect of and flotation pulp $\mathrm{pH}$ on extracting phosphorous.

\subsection{Effect of Flotation Concentration}

The concentration of flotation has a great influence on the physicochemical adsorption of flotation agents and minerals. As the concentration increases, the slurry viscosity increases, and the mechanical resistance between minerals increases, the adhesion between minerals and bubbles are affected, and the target minerals are easily separated from bubbles and the separation indexes are affected. On the contrary, if the concentration decreases, the concentration of flotation agents will decrease, resulting in an increase in the consumption of agents [32]. Under the premise of the same drug dose, if the concentration is too low, it will have a certain impact on the concentrate recovery.

It can be seen from Figure 8 that when the flotation concentration was $20-30 \%$, the $\mathrm{P}_{2} \mathrm{O}_{5}$ grade of phosphorus concentrate decreased from $28.66 \%$ to $28.29 \%$, and the $\mathrm{P}_{2} \mathrm{O}_{5}$ recovery increased from $63.75 \%$ to $74.87 \%$. When the flotation concentration was $35-45 \%$, the $\mathrm{P}_{2} \mathrm{O}_{5}$ grade of phosphorus concentrate decreased from $25.11 \%$ to $17.56 \%$, and the $\mathrm{P}_{2} \mathrm{O}_{5}$ recovery rate increased from $75.12 \%$ to 
$76.89 \%$. This indicates that the concentration of flotation pulp is $30 \%$, and the $\mathrm{P}_{2} \mathrm{O}_{5}$ grade and recovery rate of the obtained phosphorus concentrate are $28.29 \%$ and $73.64 \%$, respectively.

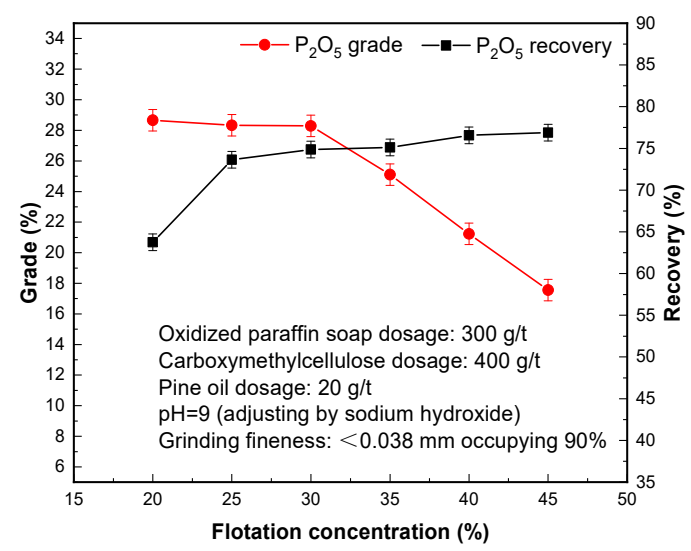

Figure 8. Effect of flotation concentration on extracting phosphorous.

\subsection{Effect of Different $p H$ Regulators}

The effect of different flotation $\mathrm{pH}$ regulators on phosphorus flotation separation is shown in Figure 9. The effect of sodium hydroxide and lime as $\mathrm{pH}$ regulator of flotation is obviously worse than that of sodium carbonate and sodium hydroxide. When sodium carbonate was used as a $\mathrm{pH}$ regulator, phosphorus concentrate with $\mathrm{P}_{2} \mathrm{O}_{5}$ grade of $28.69 \%$ and $\mathrm{P}_{2} \mathrm{O}_{5}$ recovery of $76.02 \%$ was produced. When sodium hydroxide was used as a $\mathrm{pH}$ regulator, phosphorus concentrate with $\mathrm{P}_{2} \mathrm{O}_{5}$ grade of $28.29 \%$ and $\mathrm{P}_{2} \mathrm{O}_{5}$ recovery of $74.87 \%$ was obtained. The reasons for this phenomenon are with amine cationic collector gangue mineral separation of phosphate rock minerals and effect is poorer, and $\mathrm{Ca}^{2+}, \mathrm{Mg}^{2+}$, $\mathrm{Ca}(\mathrm{OH})^{+}$, and $\mathrm{Mg}(\mathrm{OH})^{+}$in the solution later living fossil of the flotation of gangue, such as lower mineral separation, so the fatty acid collector (oxidized paraffin soap) sorted, $\mathrm{Na}_{2} \mathrm{CO}_{3}$ as $\mathrm{pH}$ adjusting agent, $\mathrm{CO}_{3}{ }^{2-}$ in the solution, and $\mathrm{HCO}_{3}{ }^{-}$and $\mathrm{Ca}^{2+}$ on the surface of the quartz. $\mathrm{Ca}^{2+}, \mathrm{Mg}^{2+}, \mathrm{Ca}(\mathrm{OH})^{+}$, and $\mathrm{Mg}(\mathrm{OH})^{+}$created $\mathrm{CaCO}_{3}$ and $\mathrm{MgCO}_{3}$, and then from the gangue mineral surface and the purpose of separation will be achieved [33-35].

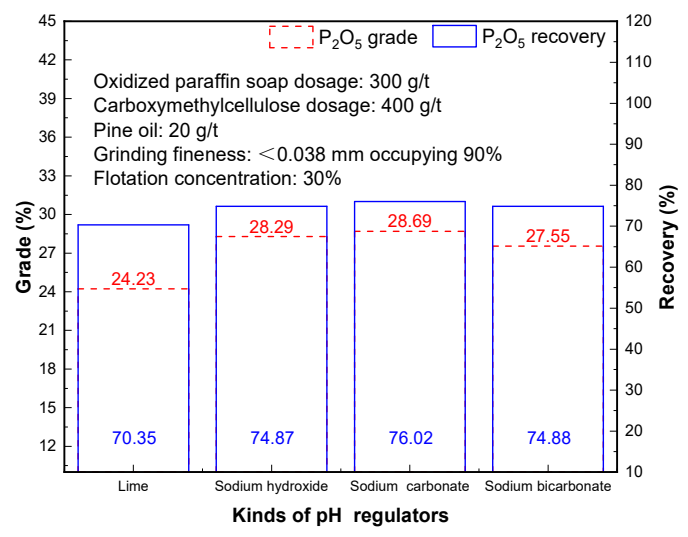

Figure 9. Effect of different $\mathrm{pH}$ regulators on extracting phosphorous.

\subsection{Effect of Stage on Flotation Scavenging Process}

Phosphorus concentrate with $\mathrm{P}_{2} \mathrm{O}_{5}$ grade of $28.69 \%$ and $\mathrm{P}_{2} \mathrm{O}_{5}$ recovery of $76.02 \%$ was obtained by one rough flotation process from the low-grade phosphorus-bearing V-Ti magnetite tailings. In order to further upgrade the phosphorus comprehensive recovery, scavenging time tests were carried out to investigate on $\mathrm{P}_{2} \mathrm{O}_{5}$ grade and recovery of froth products. The flotation scavenging process was shown in Figure 10, and the test results were shown in Table 3. 


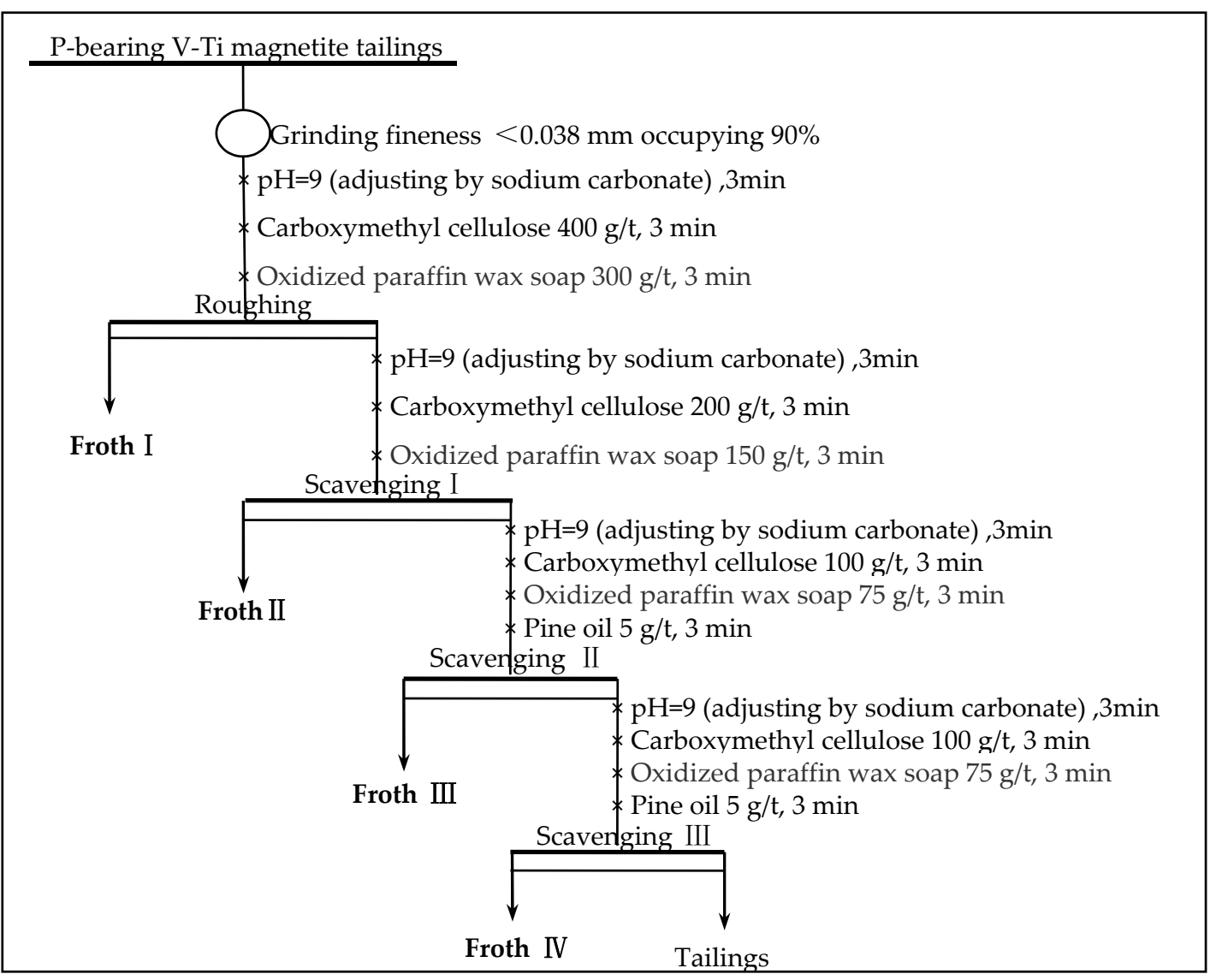

Figure 10. Time on flotation scavenging flowsheet.

Table 3. Effect of scavenging time on $\mathrm{P}_{2} \mathrm{O}_{5}$ grade and recovery in flotation (\%).

\begin{tabular}{ccccccc}
\hline \multirow{2}{*}{ Products } & \multicolumn{2}{c}{ Yield } & \multicolumn{2}{c}{$\mathbf{P}_{\mathbf{2}} \mathbf{O}_{\mathbf{5}}$ Grade } & \multicolumn{2}{c}{$\mathbf{P}_{\mathbf{2}} \mathbf{O}_{\mathbf{5}}$ Recovery } \\
\cline { 2 - 7 } & Individual & Cumulative & Individual & Cumulative & Individual & Cumulative \\
\hline FrothI & 3.78 & 3.78 & 28.69 & 28.69 & 75.83 & 75.83 \\
FrothII & 1.26 & 5.04 & 15.26 & 25.33 & 13.44 & 89.27 \\
FrothIII & 0.56 & 5.6 & 10.13 & 23.81 & 3.97 & 93.24 \\
FrothIV & 0.22 & 5.82 & 5.42 & 23.12 & 0.83 & 94.07 \\
Tailings & 94.18 & 100.00 & 0.09 & 1.43 & 5.93 & 100.00 \\
Totals & 100.00 & & 1.43 & & 100.00 & \\
\hline
\end{tabular}

The direction flotation process of phosphorous-bearing V-Ti magnetite tailings after one roughing and three scavengings can obtain the separation index of phosphorous concentrate, with a $\mathrm{P}_{2} \mathrm{O}_{5}$ grade of $23.12 \%$ and $\mathrm{P}_{2} \mathrm{O}_{5}$ recovery of $94.07 \%$. Compared with the primary roughing, the grade of cobalt decreased by $(28.69-23.12) \%=5.57$ percentage points, and the recovery of $\mathrm{P}_{2} \mathrm{O}_{5}$ increased by $(94.07-75.83) \%=18.24$ percentage points. The index increased slightly, which was related to the occurrence of phosphorous in tailings. Increasing the number of scavenging is mainly reflected in increasing the number of flotation machine slots in production, thus increasing the investment of pre-equipment. However, considering the high economic value of phosphorous, although increasing scavenging time will lead to decreasing $\mathrm{P}_{2} \mathrm{O}_{5}$ grade of phosphorous concentrate, from the perspective of comprehensive utilization of resources, it is still reasonable to obtain rough phosphorous concentrate by the direction flotation process of one roughing and three scavenging. 


\subsection{Effect of Stage on Flotation Cleaning Process}

Through the effect experiment of flotation scavenging on $\mathrm{P}_{2} \mathrm{O}_{5}$ grade and recovery, with the flotation process of one roughing and three scavenging, phosphorus rough concentrate with a $\mathrm{P}_{2} \mathrm{O}_{5}$ grade of $23.12 \%$ and $\mathrm{P}_{2} \mathrm{O}_{5}$ recovery of $94.07 \%$ was obtained. According to the quality standard of phosphorous concentrate with the grade of $\mathrm{P}_{2} \mathrm{O}_{5} \geq 28 \%$ ). Therefore, the phosphorus rough concentrate should be further processed by cleaning to improve the $\mathrm{P}_{2} \mathrm{O}_{5}$ grade. The technological process is shown in Figure 11, and the results are shown in Table 4.

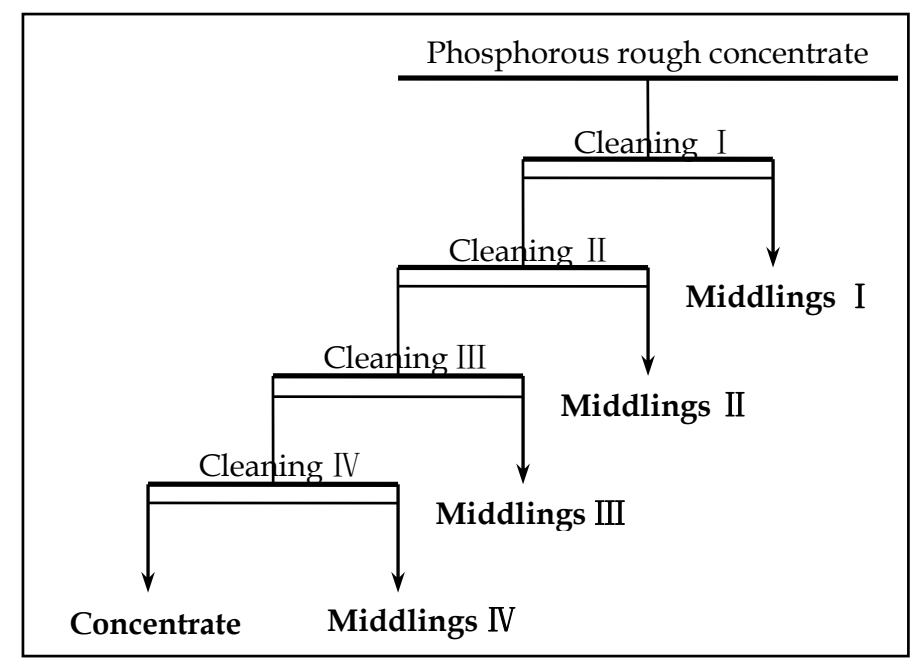

Figure 11. Time on flotation cleaning flowsheet.

Table 4. Effect of cleaning time on $\mathrm{P}_{2} \mathrm{O}_{5}$ grade and recovery in flotation (\%).

\begin{tabular}{ccccccc}
\hline \multirow{2}{*}{ Products } & \multicolumn{2}{c}{ Yield } & \multicolumn{2}{c}{$\mathbf{P}_{\mathbf{2}} \mathbf{O}_{\mathbf{5}}$ Grade } & \multicolumn{2}{c}{$\mathbf{P}_{\mathbf{2}} \mathbf{O}_{\mathbf{5}}$ Recovery } \\
\cline { 2 - 7 } & Individual & Cumulative & Individual & Cumulative & Individual & Cumulative \\
\hline Concentrate & 57.65 & 57.65 & 32.11 & 32.11 & 80.00 & 80.00 \\
MiddlingIV & 4.61 & 62.26 & 21.12 & 31.29 & 4.21 & 84.21 \\
MiddlingIII & 8.12 & 70.38 & 18.11 & 29.77 & 6.36 & 90.57 \\
MiddlingII & 11.21 & 81.59 & 11.63 & 27.28 & 5.63 & 96.20 \\
MiddlingI & 18.41 & 100.00 & 4.78 & 23.14 & 3.80 & 100.00 \\
Totals & 100.00 & & 23.14 & & 100.00 & \\
\hline
\end{tabular}

Results in Table 4 show that the improvement of $\mathrm{P}_{2} \mathrm{O}_{5}$ grade is obviously with the increase of concentrating times. Through the direction flotation process of one roughing, three scavenging, and four concentrating, the highest phosphorus separation indexes can be obtained from the low-grade $\mathrm{P}$-containing vanadium titano-magnetite tailings: $\mathrm{P}_{2} \mathrm{O}_{5}$ grade of $32.11 \%$ and $\mathrm{P}_{2} \mathrm{O}_{5}$ recovery of $79.99 \%$. Compared with the indexes of phosphorous rough concentrate before concentration, the $\mathrm{P}_{2} \mathrm{O}_{5}$ grade increased by $(32.11-23.14) \%=8.97 \%$ and cobalt recovery rate decreased by $(94.07-80.00 \% \times 94.07)$ $\%=18.81 \%$. Therefore, an optimized phosphorous concentrate with $\mathrm{P}_{2} \mathrm{O}_{5}$ grade of $29.77 \%$ and $\mathrm{P}_{2} \mathrm{O}_{5}$ recovery of $90.57 \%$ can be produced using a three-stage concentration process.

\subsection{The Whole Flotation Flowsheet Test of Recovering Phosphorous}

Combined with the technological mineralogical characteristics of phosphorous in the P-bearing V-Ti magnetite tailings, technological conditions test, scavenging, and concentrating test results, the separation process of phosphorous is optimized and the closed-circuit flotation process of one roughing, three scavenging, and three concentrating is adopted. The gangue minerals are further inhibited by increasing the amount of $\mathrm{CMC}$ in the concentrating process to ensure that the $\mathrm{P}_{2} \mathrm{O}_{5}$ grade of the 
phosphorous concentrate is increased to more than $30 \%$ and the test indexes of the whole process flow are also examined. The flotation process (shown as Figure 12) was used to carry out the whole process test. The results are shown in Table 5.

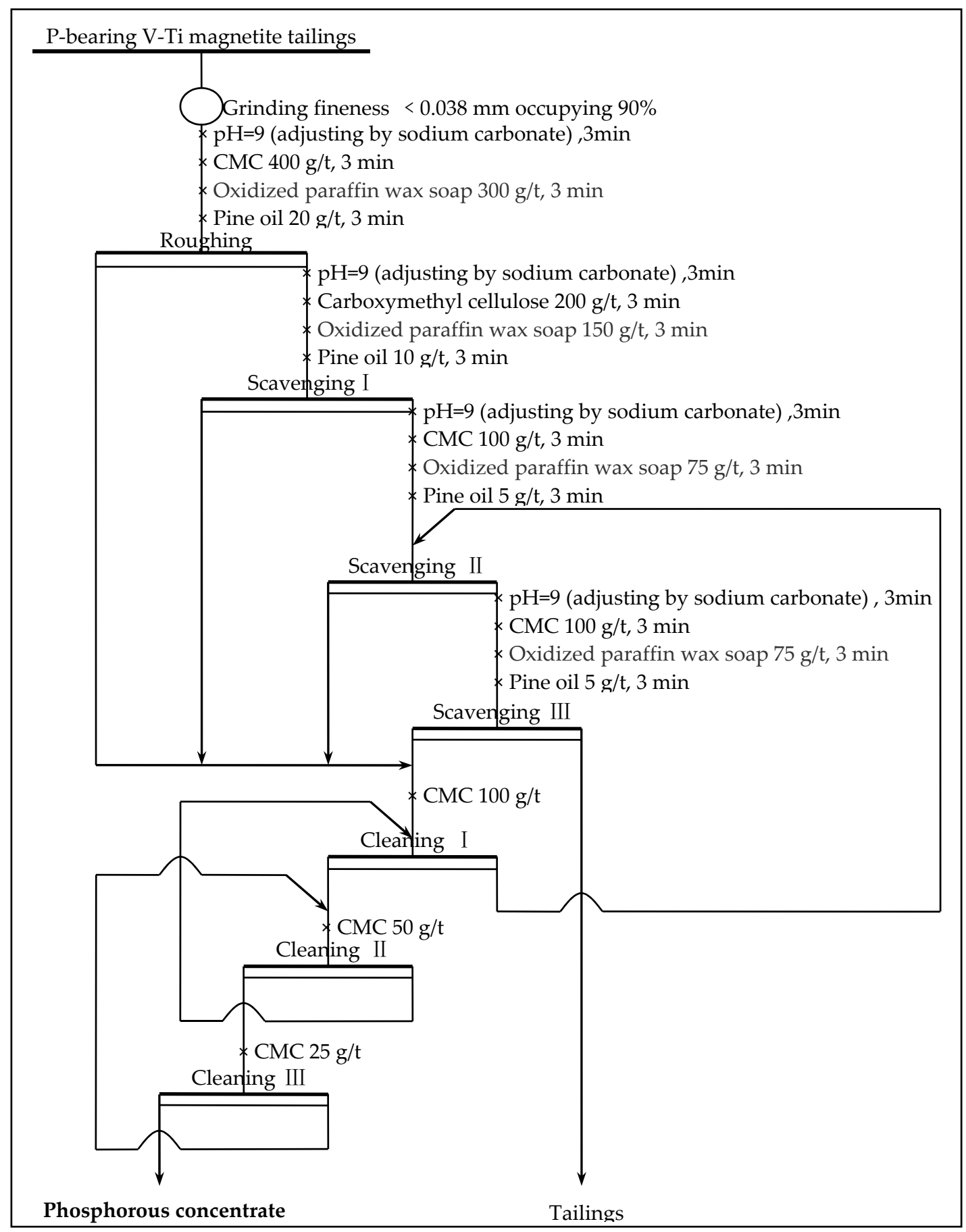

Figure 12. The whole direction flotation flowsheet of recovering phosphorous. 
Table 5. Results of the whole flotation test flowsheet of recovering phosphorus (\%).

\begin{tabular}{|c|c|c|c|c|}
\hline Repeated & Products & Yield & $\mathrm{P}_{2} \mathrm{O}_{5}$ Grade & $\mathrm{P}_{2} \mathrm{O}_{5}$ Recovery \\
\hline 1 & $\begin{array}{l}\text { Phosphorus } \\
\text { concentrate }\end{array}$ & 4.05 & 31.26 & 87.94 \\
\hline 2 & $\begin{array}{l}\text { Phosphorus } \\
\text { concentrate }\end{array}$ & 3.85 & 31.86 & 87.56 \\
\hline 3 & $\begin{array}{l}\text { Phosphorus } \\
\text { concentrate }\end{array}$ & 4.11 & 31.04 & 88.62 \\
\hline 4 & $\begin{array}{l}\text { Phosphorus } \\
\text { concentrate }\end{array}$ & 3.94 & 31.25 & 87.96 \\
\hline \multirow{2}{*}{\multicolumn{2}{|c|}{ Range $\left(R=E_{\max }-E_{\min }\right)$}} & 3.99 & 31.35 & 88.02 \\
\hline & & 0.26 & 0.82 & 1.06 \\
\hline \multicolumn{2}{|c|}{ Arithmetic mean error $\left(\delta=\frac{\sum_{i=1}^{N}\left|d_{i}\right|}{N}\right)$} & 0.09 & 0.33 & 0.30 \\
\hline \multicolumn{2}{|c|}{ um square variation $\left(S S=\sum_{i=1}^{N} d_{i}^{2}=\sum_{i=1}^{N}\left(E_{i}-\bar{E}\right)^{2}\right)$} & 0.04 & 0.79 & 0.37 \\
\hline \multicolumn{2}{|c|}{ Average deviation $\left(M S=\frac{S S}{f}\right)$} & 0.01 & 0.26 & 0.12 \\
\hline \multicolumn{2}{|c|}{ Standard deviation $\left(s=\sqrt{\frac{\sum\left(E_{i}-\bar{E}\right)^{2}}{N-1}}=\sqrt{M S}\right)$} & 0.32 & 0.51 & 0.35 \\
\hline
\end{tabular}

This study adopted the direction flotation process of one roughing, three scavengings, and three cleanings to recover phosphorous from the low-grade P-bearing V-Ti magnetite tailings, obtaining the phosphorous concentrate with a $\mathrm{P}_{2} \mathrm{O}_{5}$ grade of $31.35 \%$ and $\mathrm{P}_{2} \mathrm{O}_{5}$ recovery of $88.02 \%$, which were superior to the single-condition test results, and further showed that the flotation process had good repeatability.

\subsection{Analysis and Characterization of Phosphous Concentrate}

Low grade P-Containing vanadium titano-magnetite tailings from iron and titanium separation in the Miyi Region were treated using a direction flotation process. The separation indexes of phosphorous concentrate with a $\mathrm{P}_{2} \mathrm{O}_{5}$ grade of $31.25 \%$ and $\mathrm{P}_{2} \mathrm{O}_{5}$ recovery of $87.94 \%$ were obtained, realizing the recovery of valuable element phosphorous. The main chemical composition of phosphorous concentrate was analyzed by XRF smear quantitative analysis method, and the results are shown in Table 6 . The main mineral of phosphorous concentrate was analyzed and characterized by X-ray diffraction and scanning electron microscope-energy disperse spectroscopy (SEM-EDS). The analysis and characterization of XRD and SEM-EDS results were shown in Figures 13 and 14 respectively.

Table 6. Main chemical composition analysis of phosphorous concentrate (\%).

\begin{tabular}{cccccccccc}
\hline $\mathbf{P}_{2} \mathbf{O}_{5}$ & $\mathrm{TiO}_{2}$ & $\mathbf{S}$ & $\mathbf{F e}$ & $\mathrm{Na}_{\mathbf{2}} \mathbf{O}$ & $\mathbf{K}_{\mathbf{2}} \mathbf{O}$ & $\mathbf{C a O}$ & $\mathrm{Al}_{2} \mathbf{O}_{3}$ & $\mathbf{M g O}$ & $\mathbf{S i O}_{2}$ \\
\hline 31.25 & 1.56 & 0.11 & 4.63 & 3.29 & 0.36 & 6.96 & 16.29 & 8.67 & 20.73 \\
\hline
\end{tabular}

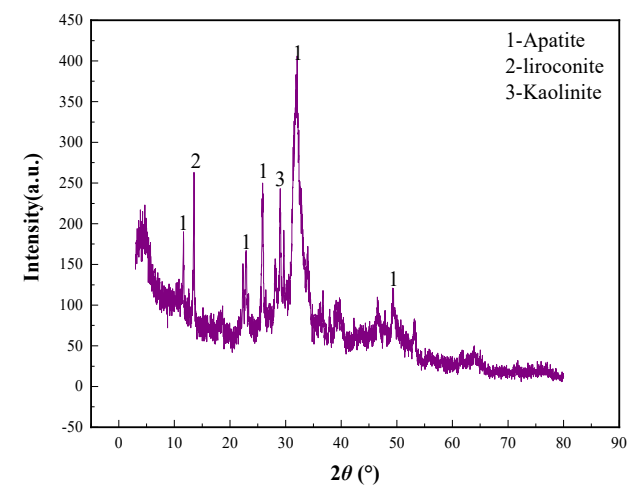

Figure 13. XRD diffractograms of the P-Containing V-Ti magnetite tailings. 

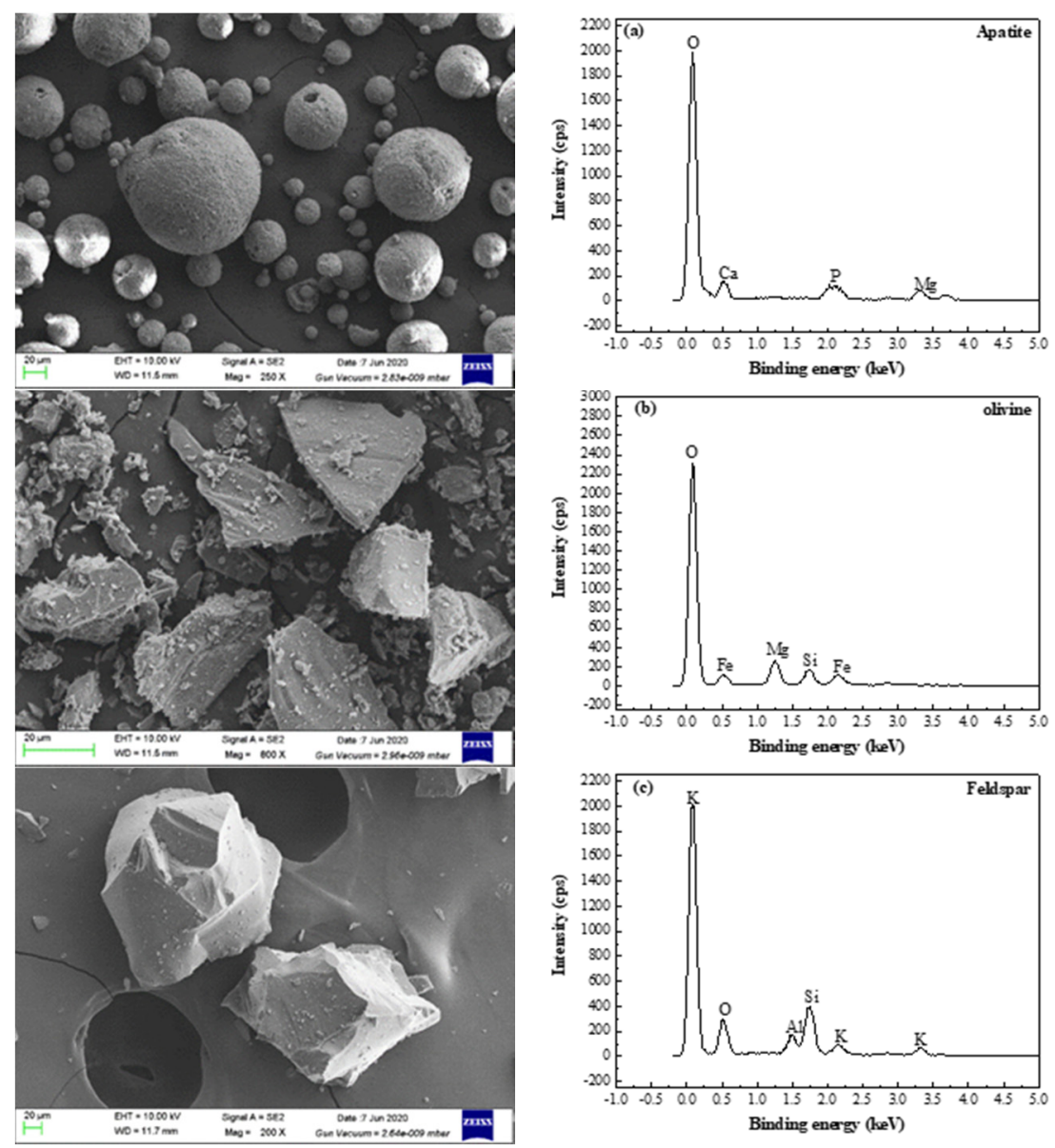

Figure 14. SEM-EDS images of apatite (a), olivine (b), and feldspar (c).

Analysis and characterization results from Table 6 and Figures 13 and 14 show that direction flotation process of one roughing, three scavengings, and three cleanings was suitable for recovering phosphorous from the low-grade P-bearing Vi-Ti magnetite tailings. Most gangue minerals enter the flotation tailings, and a phosphorus concentrate with $\mathrm{P}_{2} \mathrm{O}_{5}$ grade of $31.25 \%$ was obtained. Compared with the P-bearing vanadium titano-magnetite, gangue minerals such as olivine, hornblende, feldspar, chlorite, mica, quartz, dolomite, and calcite decrease obviously after flotation. The main minerals in phosphorous concentrate are apatite, olivine, and feldspar.

\section{Conclusions}

Based on the direct flotation results of extracting phosphorous obtained in this study, we drew the main following conclusions:

(1) The low-grade P-bearing V-Ti magnetite tailings sample was collected from a V-Ti magnetite dressing plant by magnetic separation and flotation in the Miyi area of China, and the P-bearing $\mathrm{V}$-Ti magnetite tailings contained $\mathrm{P}_{2} \mathrm{O}_{5}$ of $1.42 \%$. Apatite was the main valuable mineral; gangue minerals were mica, chlorite, feldspar, calcite, etc.

(2) The effect of different flotation conditions on phosphorus separation shows that using oxidized paraffin soap as flotation collector of phosphate minerals and carboxymethylcellulose as gangue mineral inhibitor can effectively recover the valuable element phosphorus in vanadium-titanium magnetite tailings. Phosphorous concentrate with a $\mathrm{P}_{2} \mathrm{O}_{5}$ grade of $31.35 \%$ and $\mathrm{P}_{2} \mathrm{O}_{5}$ recovery of $88.02 \%$ was obtained by a direction flotation process of one roughing, three scavengings, and three cleanings from the P-bearing V-Ti magnetite tailings. The extraction of phosphorus is remarkable, 
and the efficient utilization of phosphorous of low-grade phosphorous-bearing V-Ti tailings in the Miyi region of China can be realized finally.

(3) Studies of the characterization and analysis of phosphorous concentrate by XRD, SEM, and EDS indicated that the main minerals in phosphorous concentrate are apatite, olivine, and feldspar. It also further shows that carboxymethylcellulose, as an inhibitor of gangue ore, can significantly reduce the gangue mineral content in phosphorus concentrate, such as most gangue minerals olivine, hornblende, feldspar, chlorite, mica, quartz, dolomite, and calcite enter into flotation tailings. In addition, hornblende, as one of the main scandium bearing minerals in vanadium-titanium magnetite tailings, enters into flotation tailings, creating favorable conditions for the next step of scandium separation and extraction.

Author Contributions: This is a joint work of the six authors; each author was in charge of their expertise and capability: J.X.: writing, formal analysis, investigation, and original draft preparation; C.C. and W.D.: conceptualization; Y.P.: validation; T.C. and K.Z.: methodology. All authors have read and agreed to the published version of the manuscript.

Funding: This work was supported by the Sichuan Science and Technology Program (Grant Nos.2019FS0452, Nos.2019FS0451, and Nos.2018FZ0092); China Geological Big Survey (Grant No. DD20190694); Key Laboratory of Sichuan Province for Comprehensive Utilization of Vanadium and Titanium Resources Foundation (2018FTSZ35).

Conflicts of Interest: The authors declare no conflict of interest. The funders had no role in the design, analyses, and interpretation of any data of the study.

\section{References}

1. Vaccari, D.A.; Powers, S.M.; Liu, X. Demand-Driven Model for Global Phosphate Rock Suggests Paths for Phosphorus Sustainability. Environ. Sci. Technol. 2019, 53, 10417-10425. [CrossRef] [PubMed]

2. Abouzeid, A.Z.M. Physical and thermal treatment of phosphate ores-An overview. Int. J. Miner. Process. 2008, 85, 59-84. [CrossRef]

3. Owens, C.L.; Nash, G.R.; Hadler, K.; Fitzpatrick, R.S.; Anderson, C.G.; Wall, F. Apatite enrichment by rare earth elements: A review of the effects of surface properties. Adv. Colloid Interface Sci. 2019, 265, 14-28. [CrossRef] [PubMed]

4. Gharabaghi, M.; Irannajad, M.; Noaparast, M. A review of the beneficiation of calcareous phosphate oresusing organic acid leaching. Hydrometallurgy 2010, 103, 96-107. [CrossRef]

5. Blazy, P.; Jdid, E.A. Removal of ferriferous dolomite by magnetic separation from the Egyptian Abu Tartur phosphate ore. Int. J. Min. Process. 1997, 49, 49-58. [CrossRef]

6. Reis, A.S.; Reis, A.M.; Demuner, L.R.; Barrozo, M.A.S. Effect of bubble size on the performance flotation of fine particles of a low-grade Brazilian apatite ore. Powder Technol. 2019, 356, 884-891. [CrossRef]

7. Lavrinenko, A.A.; Shrader, E.A.; Kharchikov, A.N.; Kunilova, I.V. Apatite flotation from brazilite-apatite-magnetite ore. J. Min. Sci. 2019, 49, 811-818. [CrossRef]

8. Oliveira, M.S.; Santana, R.C.; Ataide, C.H.; Barrozo, M.A.S. Recovery of apatite from flotation tailings. Sep. Purif. Technol. 2011, 79, 79-84. [CrossRef]

9. Xiao, J.H.; Zhang, Y.S. Recovering Cobalt and Sulfur in Low Grade Cobalt-Bearing V-Ti Magnetite Tailings Using Flotation Process. Processes 2019, 7, 536. [CrossRef]

10. Alsafasfeh, A.; Alagha, L. Recovery of Phosphate Minerals from Plant Tailings Using Direct Froth Flotation. Minerals 2017, 7, 145. [CrossRef]

11. Matiolo, E.; Couto, H.J.B.; Teixeira, M.F.D.; De Almeida, R.N.; De Freitas, A.S. A Comparative Study of Different Columns Sizes for Ultrafine Apatite Flotation. Minerals 2019, 9, 391. [CrossRef]

12. Xiao, J.H.; Zhang, Y.S. Extraction of Cobalt and Iron from Refractory Co-Bearing Sulfur Concentrate. Processes 2020, 8, 200. [CrossRef]

13. Knipping, J.L.; Webster, J.D.; Simon, A.C.; Holtz, F. Accumulation of magnetite by flotation on bubbles during decompression of silicate magma. Sci. Rep. 2019, 9, 3852. [CrossRef]

14. De Oliveira, P.; Mansur, H.; Mansur, A.; Da Silva, G.; Peres, A.E.C. Apatite flotation using pataua palm tree oil as collector. J. Mater. Res. Technol. 2019, 8, 4612-4619. [CrossRef] 
15. Wonyen, D.G.; Kromah, V.; Gibson, B.; Nah, S.; Chelgani, S.C. A Review of Flotation Separation of Mg Carbonates (Dolomite and Magnesite). Minerals 2019, 8, 354. [CrossRef]

16. Teague, A.J.; Lollback, M.C. The beneficiation of ultrafine phosphate. Min. Eng. 2012, 27-28, 52-59. [CrossRef]

17. Xiao, J.H.; Zou, K.; Ding, W.; Peng, Y.; Chen, T. Extraction of Lead and Zinc from a Rotary Kiln Oxidizing Roasting Cinder. Metals 2020, 10, 465. [CrossRef]

18. Ribeiro, R.C.C.; Correia, J.C.G.; Monte, M.B.M.; Seidl, P.R.; Mothe, C.G.; Lima, C.A. Cashew gum: A new depressor for limestone in the phosphate minerals flotation. Miner. Eng. 2003, 16, 873-875. [CrossRef]

19. Xiao, J.H.; Peng, Y.; Ding, W.; Chen, T.; Zou, K.; Wang, Z. Recovering Scandium from Scandium Rough Concentrate Using Roasting-Hydrolysis-Leaching Process. Processes 2020, 8, 365. [CrossRef]

20. Peng, Y.; Xiao, J.H.; Deng, B.; Wang, Z.; Liu, N.Y.; Ding, W.; Chen, T.; Wu, Q. Study on separation of fine-particle ilmenite and mechanism using flocculation flotation with sodium oleate and polyacrylamide. Physicochem. Probl. Miner. Process. 2020, 56, 162-173.

21. Guimarães, R.C.; Araujo, A.C.; Peres, A.E.C. Reagents in igneous phosphate ores flotation. Min. Eng. 2005, 18, 199-204. [CrossRef]

22. Patra, A.; Taner, H.A.; Bordes, R.; Holmberg, K.; Larsson, A.C. Selective flotation of calcium minerals using double-headed collectors. J. Dispersion Sci. Technol. 2019, 40, 1205-1216. [CrossRef]

23. Xiao, J.H.; Zhou, L.L. Increasing Iron and Reducing Phosphorus Grades of Magnetic-Roasted High-Phosphorus Oolitic Iron Ore by Low-Intensity Magnetic Separation-Reverse Flotation. Processes 2019, 7, 388. [CrossRef]

24. Santana, R.C.; Farnese, A.C.C.; Fortes, M.C.B.; Ataide, C.H.; Barrozo, M.A.S. Influence of particle size and reagent dosage on the performance of apatite flotation. Sep. Purif. Technol. 2008, 64, 8-15. [CrossRef]

25. Hoang, D.H.; Hassanzadeh, A.; Peuker, U.A.; Rudolph, M. Impact of flotation hydrodynamics on the optimization of fine-grained carbonaceous sedimentary apatite ore beneficiation. Powder Technol. 2019, 345, 223-233. [CrossRef]

26. Santana, R.C.; Duarte, C.R.; Ataide, C.H.; Barrozo, M.A.S. Flotation selectivity of phosphate ore: Effect of particle size and reagent concentration. Sep. Sci. Technol. 2011, 46, 1511-1518. [CrossRef]

27. Reis, A.S.; Barrozo, M.A.S. A study on bubble formation and its relation with the performance of apatite flotation. Sep. Purif. Technol. 2016, 161, 112-120. [CrossRef]

28. Santos, M.A.; Santana, R.C.; Capponi, F.; Ataíde, C.H.; Barrozo, M.A.S. Effect of ionic species on the performance of apatite flotation. Sep. Purif. Technol. 2010, 76, 15-20. [CrossRef]

29. Xiao, J.H.; Ding, W.; Peng, Y.; Chen, T.; Zou, K.; Wang, Z. Extraction of Nickel from Garnierite Laterite Ore Using Roasting and Magnetic Separation with Calcium Chloride and Iron Concentrate. Minerals 2020, 10, 352. [CrossRef]

30. Vieira, A.M.; Peres, A.E.C. The effect of amine type, $\mathrm{pH}$, and size range in the flotation of quartz. Min. Eng. 2007, 20, 1008-1013. [CrossRef]

31. Han, Y.; Han, S.; Kim, B.; Yang, J.; Choi, J.; Kim, K.; You, K.S.; Kim, H. Flotation separation of quartz from apatite and surface forces in bubble-particle interactions: Role of $\mathrm{pH}$ and cationic amine collector contents. J. Ind. Eng. Chem. 2019, 70, 107-115. [CrossRef]

32. Filippov, L.O.; Filippova, I.V.; Lafhaj, Z.; Fornasiero, D. The role of a fatty alcohol in improving calcium minerals flotation with oleate. Colloids Surf. A 2019, 560, 410-417. [CrossRef]

33. Dos Santos, M.A.; Santana, R.C.; Capponi, F.; Ataide, C.H.; Barrozo, M.A.S. Influence of the Water Composition on the Selectivity of Apatite Flotation. Sep. Sci. Technol. 2012, 47, 606-612. [CrossRef]

34. Tang, J.Y.; Zhang, Y.M.; Bao, S.X. The Effect of $\mathrm{Ca}^{2+}$ and $\mathrm{Mg}^{2+}$ on the Dispersion and Flocculation Behaviors of Muscovite Particles. Minerals 2016, 6, 93. [CrossRef]

35. Azizi, D.; Larachi, F. Surface interactions and flotation behavior of calcite, dolomite and ankerite with alkyl hydroxamic acid bearing collector and sodium silicate. Colloids Surf. A 2018, 537, 126-138. [CrossRef]

(C) 2020 by the authors. Licensee MDPI, Basel, Switzerland. This article is an open access article distributed under the terms and conditions of the Creative Commons Attribution (CC BY) license (http://creativecommons.org/licenses/by/4.0/). 